Arena 



\title{
Um enfoque mais amplo para o Jornalismo Científico*
}

\author{
Carlos Henrique Fioravanti**
}

\section{Resumo}

Neste ensaio, com base em propostas de outros jornalistas, em recomendações dos idealizadores da Teoria Ator-Rede e na observação da prática da produção científica, apresenta-se um enfoque ampliado do Jornalismo Científico, que considera a ciência como um trabalho coletivo e histórico, marcado pela incerteza e pela diversidade de atores. Comparado com o enfoque clássico predominante, que foca os cientistas de modo isolado e considera a ciência como um processo linear, desprovido de conflitos internos e previsível, o Enfoque Ampliado poderia ajudar os jornalistas a descrever a ciência de modo menos otimista, a evitar os equívocos mais comuns no relato de descobertas científicas, a diversificar as fontes de informação e a desenhar um quadro mais realista da ciência.

Palavras chave: Jornalismo Científico. Teoria do Ator-Rede. Descoberta e desenvolvimento de fármacos.

\section{A wider approach to Science Journalism Abstract}

In this Essay, based on proposals by other journalists, recommendations from the creators of the Actor-Network Theory and the observation of scientific practice, I am presenting a wider approach to Science Journalism, taking science as a collective, historical work, marked by uncertainty and a diversity of actors. Compared to the classical, predominant approach, which focuses on

* Meus agradecimentos a Regina Fioravanti, Alison Askew, a meus colegas Marcos Pivetta, Ricardo Zorzetto, Rodrigo de Oliveira Andrade e Bruno de Pierro e aos professores Alysson Muotri, Carlos Escobar, Renata Wentzcovitch e Till Hanebuth que forneceram comentários valiosos para melhorar as versões anteriores deste artigo.

** Jornalista científico, doutor, pesquisador em história da medicina no Brasil. São Paulo-SP, Brasil. E-mail: chfioravanti@gmail.com 
individual scientists and considers science as linear, without internal conflicts, and a predictable process, the Wider Approach may help journalists write about science in a less naive way, avoiding the most common mistakes while reporting scientific achievements, to diversify the source of the information and draw a more realistic picture of science.

Keywords: Science Journalism. Actor Network Theory. Drug discovery and development.

\section{Un enfoque más amplio para el periodismo científico Resumen}

En este ensayo, basado en propuestas de otros periodistas, en recomendaciones de los creadores de la Teoría del Actor-Red y en la observación de la práctica de la producción científica, presento un enfoque más amplio de Periodismo Científico, que tiene la ciencia como una obra histórica y colectiva, marcada por la incertidumbre y la diversidad de actores. En comparación con el enfoque clásico predominante, que se centra en los investigadores individuales y considera la ciencia cómo un proceso lineal, ausente de los conflictos internos y predecible, el enfoque más amplio podría ayudar a los periodistas para describir la ciencia de una manera menos ingenua, evitar los errores más comunes en la Comunicación de los resultados científicos, diversificar las fuentes de información, y dibujar una imagen más realista de la ciencia.

Palabras clave: Periodismo científico. Teoría del actor-red. Descubrimiento y desarrollo de fármacos.

\section{Propostas esparsas}

revista Nature publicou dois ensaios notáveis sobre Jor-
nalismo Científico em 2009. No primeiro, Toby Murcott,
correspondente de ciência da BBC, sugere que o processo de produção da ciência, normalmente apresentado como algo misterioso, precisa ser aberto, os jornalistas que escrevem sobre ciência deveriam ser mais ativos, questionadores e propositivos, como os jornalistas que escrevem sobre política, apontam erros e contradições e participam do debate político com comentários relevantes. O mesmo ocorre com o modelo atual de Jornalismo Científico, em que o jornalista age como um sacerdote, tomando a informação de uma autoridade, o cientista, e comunicando-a à congregação, precisa ser revisto, em busca de uma visão mais aprofundada e crítica das notícias sobre ciência (MURCOTT, 
2009). Em seguida, na mesma edição da Nature, Boyce Rensberger, jornalista que escreveu sobre ciência por 32 anos no Washington Post e no The New York Times, reconhece que o repórter de ciência evoluiu bastante, passando do que ele chama de líderes de torcida (cheerleaders) para cães de guarda (watchdogs), mas ainda carecem de distanciamento e de independência para que possam fazer relatos abrangentes e imparciais (RENSBERGER, 2009).

Abordagens metodológicas e propostas de aperfeiçoamento da prática profissional como as de Murcott e de Rensberger ainda são raras no Jornalismo Científico, marcado por uma extrema dependência dos papers (artigos científicos) e de press releases (MURCOTT, 2009) e por uma baixa variedade de fontes de informação - em geral os entrevistados são apenas os mesmos cientistas que anunciam os resultados. Em busca de formas mais abrangentes de escrever sobre ciência e de uma visão mais ampla sobre a produção de ciência, tenho reunido estratégias de ação explícitas ou tácitas de jornalistas e de publicações de maior prestígio - revistas científicas como Nature, Science e PNAS enfatizam a absoluta precisão das informações e a preocupação em não exagerar a importância da notícia; o caderno de ciência do The New York Times expõe a possibilidade de apresentar as descobertas como narrativas humanas vivas; a revista The Economist oferece uma exemplar combinação de respeito e dúvida sobre as descobertas científicas. Com a mesma finalidade, de modo complementar e convergente, tenho adotado as ferramentas conceituais da Teoria do Ator-Rede (TAR). A TAR considera que a produção de conhecimento decorre da interação de grupos distintos de atores, não apenas de cientistas, com interesses igualmente distintos. A ciência torna-se então um fenômeno social e coletivo, que pode emergir, avançar ou morrer como resultado de negociações, conflitos e impasses entre os interessados. Na ciência, afirma Bruno Latour, um dos idealizadores da TAR, a "construção de um fato é um processo tão coletivo que uma pessoa sozinha só constrói sonhos, alegações e sentimentos, mas não fatos" (LATOUR, 2000, p.70).

Em um artigo anterior, apresentei as possibilidades de uso dos princípios da TAR - como a possibilidade de seguir os atores 
(humanos e não-humanos) e as conexões entre eles para entender o que aconteceu e deve acontecer - como forma de aprimorar a cobertura de assuntos científicos (FIORAVANTI; VELHO, 2010). Agora, integrando propostas de outros jornalistas e de idealizadores da TAR e a observação da prática da produção científica, apresento o chamado Enfoque Ampliado do Jornalismo Científico, em busca de uma visão mais abrangente de ciência. O Enfoque Ampliado se propõe a ir além da visão simplista e otimista, predominante no Jornalismo Científico.

\section{otimismo persiste}

Em abril de 1983, uma das mais importantes revistas semanais do Brasil publicou um avanço científico notável: a fusão de células de boi com as de tomate, resultando em uma célula híbri$\mathrm{da}$, o boimate. Os jornalistas da revista entrevistaram cientistas brasileiros respeitados, que asseguraram que a emergente biologia molecular poderia de fato fazer coisas fantásticas como aquele híbrido, anunciado por uma equipe liderada por Barry McDonalds e William Winpey, do Departamento de Biologia da Universidade de Hamburgo. Seria um salto na ciência, já que o cruzamento entre seres de espécies diferentes - ou espécies muito distantes, como neste caso - ainda era impossível (OS FRUTOS..., 1983, p.84). Três meses depois, o jornal Estado de São Paulo apresentou o erro em uma reportagem espirituosa com o título "Revista descobre "hambúrguer mágico'": a notícia era uma brincadeira de primeiro de abril da revista inglesa New Scientist. O nome dos cientistas citados na matéria da revista eram, na realidade, referências às redes de restaurantes McDonald's e Wimpy's (NEW SCIENTIST, 1983; REVISTA..., 1983, p.20). Uma das lições do boimate é que os jornalistas não deveriam simplesmente aceitar a pesquisa cientifica como inquestionável.

Em 30 anos, o Jornalismo Científico melhorou bastante no Brasil, mas a falta de conhecimento básico sobre a produção de ciência mantém o otimismo vivo. Em 2005, um repórter do Estado escreveu que cientistas de dois centros de pesquisa do país tinham 
encontrado um medicamento novo contra Trypanosoma cruzi, o protozoário causador da doença de Chagas, embora os testes de segurança e eficácia em modelos animais e em seres humanos ainda não tivessem sido feitos (CASTRO, 2005). O repórter deveria saber que a identificação de novas moléculas promissoras é apenas o primeiro passo de um caminho longo, difícil e caro que pode levar a um novo medicamento, se tudo correr bem.

Como parte de minha pesquisa de doutorado, acompanhei a trajetória de divulgação de 26 moléculas apresentadas nos últimos 15 anos como medicamentos promissores em revistas científicas internacionais e em jornais e revistas do Brasil. As moléculas representavam novas possibilidades de tratamento contra câncer, tuberculose, dor, inflamação, hipertensão, mal de Alzheimer, artrite, epilepsia, micose e úlceras, além de problemas de saúde pública típicos de países tropicais como doença de Chagas e esquistossomose. Os cientistas responsáveis por essas pesquisas afirmaram, por meio da mídia, que essas moléculas seriam avaliadas em seres humanos ou estariam disponíveis como medicamentos em alguns anos. Por várias razões, até agora nenhuma dessas moléculas cumpriu as metas prometidas (FIORAVANTI, 2010a; 2010b).

Como jornalistas, pesquisadores e leitores, frequentemente presumimos a existência de conexões entre centros de pesquisa, empresas e governo que de fato não existem, desse modo prejudicando a esperada continuidade de uma pesquisa científica. Mesmo a existência de conexões entre os atores supostamente interessados em novos medicamentos não é o bastante para assegurar a continuidade do trabalho de pesquisa e desenvolvimento, já que os candidatos a medicamentos têm de superar uma série de testes para serem aprovados e comercializados. Os conflitos podem continuar mesmo depois que um medicamento já está sendo vendido, com os pesquisadores acadêmicos solicitando informações sobre sua segurança e eficácia e os órgãos do governo e empresas recusando-se a fornecê-las, como discutido com maestria no livro Bad Pharma (GOLDACRE, 2012). Diferentemente das notícias de esportes, não há conclusões simples no incerto mundo da ciência. Vários cientistas já me aconselharam a "não acreditar muito na ciência". 
De modo similar, não deveríamos acreditar em medicamentos ou na moderna medicina sem desconfiar de seus limites.

Um perfil abrangente dos jornalistas de ciência em vários países conduzido por uma equipe do SciDev indica que poderíamos ir além dos limites habituais. A maioria dos 951 entrevistados disse que o bom Jornalismo Científico implica o relato dos fatos "de modo independente, neutro e original"; dois terços dos entrevistados consideraram que os jornalistas de ciência "não são criticamente astutos o bastante quando escrevem ou trabalham em suas reportagens" (RAMOS, 2012). Raramente os jornalistas suspeitam de metas irrealistas, como fez um jornalista do Financial Times ao examinar um projeto de 1,1 bilhão de euros, com a previsão de dez anos de duração, para simular o funcionamento de todo o cérebro humano, apresentado em janeiro de 2013 pela Comissão Europeia (MARCUS, 2013). Igualmente raras são as matérias jornalísticas que discutem os limites dos testes genéticos ou questionam axiomas científicos, como o que assegura que os genes causam doenças. "A verdade é que os genes só muito raramente é que causam doenças", argumentou David Shenk na revista The Atlantic (SHENK, 2012; KOLATA, 2013).

\section{Enfoque Ampliado}

Visões simplistas da ciência caracterizam o que chamarei aqui de Enfoque Clássico do Jornalismo Científico. O Enfoque Clássico está focado em resultados positivos, centra-se no cientista tomado individualmente e considera a ciência como um processo linear, pacífico e previsível. Essa estratégia de apresentar as notícias de ciência tem funcionado, mas acredito que precisa de alguns ajustes. Uma possibilidade de aprimoramento é o Enfoque Ampliado, que combina estratégias de jornalistas e de publicações de maior prestígio, propostas da TAR e a observação da prática da produção científica.

O objetivo do Enfoque Ampliado é ampliar a visão expressa no Enfoque Clássico, atualmente o modo mais adotado de apresentar as descobertas científicas. O Enfoque Clássico predomina no Brasil, no qual as conclusões dos cientistas são geralmente apresentadas como verdades inquestionáveis. Em uma pesquisa recente, os principais jornais do Brasil foram os que deram menos espaço às vozes 
céticas sobre mudanças climáticas, indicando como a perspectiva de certeza predomina sobre a dúvida e o debate, em comparação com jornais similares da China, França, Índia, Inglaterra e Estados Unidos (PAINTER, 2011).

O Enfoque Ampliado implica mudanças sutis, mas relevantes, no modo habitual de lidar com a ciência. Os artigos científicos, o ponto de partida mais comum para as notícias de ciência, poderiam ser vistos como base para bons relatos, como se faz com regularidade na Nature, Science, The New York Times e outras publicações de primeira linha, não como justificativa para as matérias. Enquanto o Enfoque Clássico privilegia o episódico (hot news) sobre qualquer possibilidade de debate sobre as implicações das descobertas científicas, o Enfoque Ampliado valoriza a possibilidade de promover debates a partir de notícias do momento.

$O$ tom e a linguagem poderiam também ser levemente diferentes. Poderíamos ver a ciência de um modo menos formal, com menos otimismo e mais incerteza, já que sabemos que a ciência e a tecnologia raramente avançam como esperado. Poderíamos também usar verbos menos enfáticos (um experimento indica ou sugere), em vez dos verbos inquestionáveis mais comuns (no Enfoque Clássico, qualquer experimento mostra ou demonstra algo, sem qualquer espaço para dúvidas, surpresas ou decepções).

Além disso, os cientistas poderiam deixar de ser vistos como heróis solitários e serem apresentados como seres mais humanos e completos. No Enfoque Clássico predomina a persona, expressando uma visão impessoal, quase heróica, enquanto no Enfoque Ampliado há espaço para o pesquisador como indivíduo, com emoção, desejo e dúvidas. Em vez de apenas enfatizar resultados positivos e a certeza sobre as conclusões de uma pesquisa, no Enfoque Ampliado resultados negativos ou duvidosos podem ser considerados. Consequentemente, a linguagem mudará do habitual "Chegará em breve..." para conclusões mais prudentes, como "Se tudo correr bem, talvez chegue logo..." ou "se esta pesquisa estiver certa, se os pesquisadores receberem apoio financeiro...”. Como resultado, a ciência emergirá como um fato histórico dependente de muitos atores, em vez de ser uma atividade limitada a apenas um cientista e ao presente, como no Enfoque Clássico (veja quadro comparativo a seguir). 


\section{Duas visões do Jornalismo Científico}

\begin{tabular}{|c|c|c|}
\hline & Enfoque Clássico & Enfoque Ampliado \\
\hline $\begin{array}{l}\text { A percepção } \\
\text { de ciência } \\
\text { por não- } \\
\text { cientistas }\end{array}$ & $\begin{array}{l}\text { A ciência é linear, desprovida } \\
\text { de conflitos internos, com } \\
\text { desenvolvimento e resultados } \\
\text { previsíveis, individual, inclui } \\
\text { poucos atores, centra-se no } \\
\text { presente, depende muito de artigos } \\
\text { científicos. }\end{array}$ & $\begin{array}{l}\text { A ciência é não-linear, resultante } \\
\text { de negociações entre pessoas com } \\
\text { interesses iguais ou diferentes, } \\
\text { segue um curso meândrico com } \\
\text { resultados imprevisíveis, é coletiva, } \\
\text { inclui muitos atores, considera } \\
\text { uma visão histórica, é menos } \\
\text { dependente de artigos científicos. }\end{array}$ \\
\hline Ritmo & Tudo é rápido e previsível. & $\begin{array}{l}\text { O avanço é lento. Obstáculos } \\
\text { e forças contrárias devem ser } \\
\text { considerados. }\end{array}$ \\
\hline Tom & $\begin{array}{l}\text { A ciência é tratada com muita } \\
\text { formalidade, como dogma; } \\
\text { predomina o otimismo sobre o } \\
\text { impacto e a continuidade das } \\
\text { pesquisas. }\end{array}$ & $\begin{array}{l}\text { Há menos formalidade e otimismo } \\
\text { e mais espaço para humor, } \\
\text { ceticismo e irreverência. }\end{array}$ \\
\hline Ênfase & $\begin{array}{l}\text { Predominam os resultados positivos } \\
\text { e a certeza sobre as conclusões das } \\
\text { pesquisas. }\end{array}$ & $\begin{array}{l}\text { Resultados negativos ou duvidosos } \\
\text { também podem ser considerados. }\end{array}$ \\
\hline Pressuposto & $\begin{array}{l}\text { Confiança no valor intrínseco } \\
\text { do trabalho científico (se é bom, } \\
\text { avançará). }\end{array}$ & $\begin{array}{l}\text { O valor intrínseco não é mais o } \\
\text { suficiente. Os avanços dependem } \\
\text { de alianças, interesses, negociações } \\
\text { e sorte. }\end{array}$ \\
\hline $\begin{array}{l}\text { Linguagem } \\
\text { jornalística }\end{array}$ & $\begin{array}{l}\text { Descritiva, distante do leitor, } \\
\text { assimétrica/impositiva (especialistas } \\
\text { versus leigos) e puramente racional. } \\
\text { A separação reina. }\end{array}$ & $\begin{array}{l}\text { Descritiva e narrativa, mais } \\
\text { próxima do leitor, mais sensível, } \\
\text { com mais interação e diálogo. }\end{array}$ \\
\hline Vocabulário & $\begin{array}{l}\text { Verbos assertivos (descobrir, } \\
\text { encontrar, mostrar, afirmar, } \\
\text { assegurar) são comuns, sem espaço } \\
\text { para dúvidas. }\end{array}$ & $\begin{array}{l}\text { Verbos menos assertivos (verificar, } \\
\text { indicar, encontrar, suspeitar, } \\
\text { acreditar, formular uma hipótese } \\
\text { sobre) e mais espaço para dúvida } \\
\text { e condicionais (se ele/ela estiver } \\
\text { certo/certa... se os próximos } \\
\text { experimentos confirmarem...). }\end{array}$ \\
\hline $\begin{array}{l}\text { A imagem } \\
\text { dos } \\
\text { cientistas }\end{array}$ & $\begin{array}{l}\text { Predomina a persona, expressando } \\
\text { uma visão impessoal, quase heroica. }\end{array}$ & $\begin{array}{l}\text { Mais espaço para o pesquisador } \\
\text { como individuo. }\end{array}$ \\
\hline Atores & $\begin{array}{l}\text { Poucos e exclusivamente humanos. } \\
\text { Predomina a abstração. A ação } \\
\text { depende somente da vontade das } \\
\text { pessoas. }\end{array}$ & $\begin{array}{l}\text { Muitos atores, incluindo não- } \\
\text { humanos: micróbios, documentos, } \\
\text { objetos, equipamentos, instituições. } \\
\text { A ação é o resultado da interação } \\
\text { entre eles e não é mais apenas a } \\
\text { expressão do desejo das pessoas. }\end{array}$ \\
\hline $\begin{array}{l}\text { Papel do } \\
\text { jornalista }\end{array}$ & $\begin{array}{l}\text { Intermediário (apenas transmitir } \\
\text { informação) }\end{array}$ & $\begin{array}{l}\text { Mediador (acrescentar valor à } \\
\text { informação e refletir sobre suas } \\
\text { consequências) }\end{array}$ \\
\hline $\begin{array}{l}\text { Papel do } \\
\text { entrevistado }\end{array}$ & $\begin{array}{l}\text { O cientista é apenas o fornecedor de } \\
\text { informações e explicações sobre um } \\
\text { assunto específico. }\end{array}$ & $\begin{array}{l}\text { O cientista pode ajudar a planejar a } \\
\text { reportagem, à medida que o diálogo } \\
\text { com o jornalista se torna possível. }\end{array}$ \\
\hline
\end{tabular}




\section{Uma ciência mais humana}

Em ciência, um resultado não é aceito somente se é correto ou consistente, mas também porque outras pessoas estão interessadas em aceitá-lo. Uma recusa não quer dizer que não esteja certo. $O$ exemplo mais conhecido é o modelo heliocêntrico do sistema solar proposto por Galileu, que a Igreja Católica considerou herético e mais tarde provou estar correto. No início do século 20, Alfred Wegener descreveu de modo pioneiro a deriva continental, mas a maioria dos geólogos ingleses inicialmente rejeitou as evidências porque tinha sido um alemão, não um britânico, que tinha apresentado a nova teoria, atualmente considerada essencial em geofísica (STEWART, 1986). A ciência, por ser uma atividade humana, não é lógica ou racional todo o tempo.

No Enfoque Clássico do Jornalismo Científico, os argumentos são puramente científicos e racionais, enquanto no Enfoque Ampliado os argumentos podem ser também sociais e políticos, refletindo alianças, conflitos e interesses. Os jornalistas poderiam examinar por que um resultado ou uma teoria foi aceito ou não: algo está sendo ameaçado? Um modo de fazer isso é prestar atenção às alianças ou rivalidades entre cientistas e instituições, bem como às forças políticas e econômicas que dirigem o trabalho dos cientistas. A pesquisa científica parece progredir mais rapidamente quando está ligada a interesses políticos e econômicos, na medida em que as conexões entre os interessados já estão feitas.

Poderia também ser valioso examinar a retórica: quem está falando? Que tipo de argumento ele/ela está usando? Galileu nos ensinou não só que a Terra não é o centro do Universo, mas também que a retórica pode ser mais forte que os argumentos científicos para mover - ou barrar - a ciência. Notícias fantásticas de universidades, centros de pesquisa e agência de financiamento deveriam também ser avaliadas com cuidado. As instituições têm de zelar pela imagem pública, já que a visibilidade pode assegurar a entrada de recursos, e às vezes elas pressionam cientistas a produzir notícias de impacto rapidamente. 


\section{Atores não-humanos}

Uma mudança mais significativa é o conceito de ator definido pela TAR como "qualquer coisa que modifique um estado de coisas fazendo uma diferença” (LATOUR, 2005, p.71), com a ressalva: "Se um ator não faz diferença, não é um ator" (LATOUR, 2005, p.130). As ações emergem do conjunto de competências da rede de atores à medida que as entidades são unidas (MURDOCH, 1997). Um ator só existe quando é um ator-rede, ou seja, quando está conectado com outros por meio de uma rede, um conceito que designa a "habilidade de cada ator de fazer outros atores fazer coisas inesperadas" (LATOUR, 2005, p.129). A TAR emergiu nos anos 80 com os estudos pioneiros de Latour, de Michel Callon e de John Law, que, em busca de uma nova teoria para entender fenômenos sociais, consideraram a participação de seres não-humanos como micróbios, ostras e barcos decisiva no encaminhamento ou na resolução de situações antes analisadas apenas a partir das motivações, interesses e limites humanos (LATOUR, 1983; CALLON, 1986; LAW, 1986). Atribuir papéis igualmente relevantes a atores humanos e não-humanos tornou-se, a partir daí, uma das peculiaridades dessa abordagem. No Enfoque Ampliado o conceito de ator inclui não-humanos, como micróbios, equipamentos ou instituições. Os atores não-humanos ajudam a ciência a se tornar material e concreta - e poderiam ser mais valorizados, já que enriquecem os relatos.

O Enfoque Ampliado em Jornalismo Científico valoriza detalhes, coisas ou pessoas normalmente esquecidas. Procurando por heróis, raramente consideramos outros personagens que tentaram e não alcançaram os resultados almejados, mas podem ter boas histórias para contar. Por exemplo, em 1924 e 1925 o médico André Gratia e sua assistente Sara Dath publicaram vários artigos em francês anunciando que um fungo tinha inibido o crescimento de bactérias no laboratório do Instituto Pasteur da Bélgica onde trabalhavam. Eles continuaram estudando o fenômeno, mas depois Gratia adoeceu e, quando voltou ao laboratório, os fungos que tinham levado àqueles efeitos não tinham sobrevivido. Em 
1929 Alexander Fleming observou o mesmo fenômeno em seu laboratório em Londres e publicou um artigo descrevendo sua descoberta. Quase dez anos depois seu artigo foi encontrado em Oxford por Ernest Chain, que continuou o desenvolvimento da penicilina. As pesquisas podem facilmente dar errado. Em viagens de campo para coletar animais, plantas, rochas ou sedimentos, os cientistas podem ficar doentes, os equipamentos podem quebrar, pode chover muito, e os planos ser totalmente frustrantes. Raramente vemos a ciência por dentro, mas por que não considerar esses eventos nos relatos? O Enfoque Ampliado abre espaço para a ação e para o imprevisto.

Um aspecto mais delicado do Enfoque Ampliado é o papel do jornalista, que os cientistas podem não aceitar facilmente, pelo menos no Brasil. O jornalista não é mais um intermediário, apenas transmitindo informação, como um carteiro ou um porta-voz dos cientistas, mas um mediador, refletindo com independência sobre a informação e suas consequências (ator, intermediários e mediador são termos comuns nos relatos da Teoria do Ator-Rede). À medida que aplico o Enfoque Ampliado, suspeito que a maioria dos cientistas no Brasil prefere ser o herói solitário em relatos mais simples do que compartilhar espaço e ideias com outros especialistas em reportagens mais elaboradas, apesar de nenhum deles até agora tenha protestado.

papel do entrevistado poderia ser revisto. No Enfoque Ampliado, o cientista não é mais apenas o fornecedor de informações e explicações sobre seu próprio trabalho. Pode também ser um pensador e ajudar o jornalista a planejar a reportagem, sem interferir na sua autonomia. $O$ pesquisador pode sugerir outras pessoas de outros centros de pesquisa, que poderiam ser entrevistadas, ou de outras épocas, que deveriam ser lembradas como parte do histórico da descoberta. Quando possível ou necessário, o pesquisador pode ajudar a checar as conclusões e o tom do relato, como um editor convencional em uma redação de jornal ou revista. À medida que o diálogo se torna possível e o jornalista não está mais sozinho para planejar o trabalho, a reportagem será feita com, não mais para ou sobre, um cientista. Os fotógrafos podem também oferecer 
uma assistência valiosa para planejar e editar as reportagens, que serão o resultado de um trabalho colaborativo, não mais apenas a expressão do talento científico ou jornalístico. Minha própria experiência tem mostrado que esse tipo de colaboração, em que cada parte considera os interesses do outro, é possível. $\mathrm{O}$ trabalho do jornalista não tem de ser tão solitário.

\section{Lições da floresta}

Onfoque Ampliado tem me permitido entender melhor a produção científica e aprimorar minha prática profissional. Em novembro de 2012, depois de uma viagem de 18 horas de barco, desembarquei em Maués, no estado do Amazonas, para ver uma forma nova de produzir óleo de pau-rosa, uma árvore nativa da região. Em 2011, um produtor local tinha começado a usar folhas e ramos de pau-rosa, em vez de apenas troncos, a única parte da árvore aproveitada desde o início do século 20 para extrair o óleo usado em perfumes. A inclusão de folhas e ramos na produção poderia ser vista como fácil e simples - não haveria custos extras com a matéria prima ou no processo industrial -, mas uma simples inovação como essa levou 13 anos para ser adotada.

Um pesquisador acadêmico começou a perseguir a possibilidade de extrair óleo de folhas em 1998. Ele formou uma equipe, recebeu alguns financiamentos, coletou plantas na Amazônia, testou sua hipótese em laboratório e, em 2005, ao anunciar os resultados preliminares de seus experimentos, estava otimista sobre a viabilidade de inclusão de folhas no processo tradicional de extração de óleo de pau-rosa, mas ainda tinha de convencer outras pessoas sobre suas conclusões. O produtor de Maués olhou com desconfiança - por que ninguém havia tentado antes, se era tão simples? - e gastou dois anos para fazer seus próprios testes e obter a aprovação dos clientes. Enquanto isso, uma lei federal restringiu a produção de óleo, já que o pau-rosa estava sob ameaça de extinção, outros produtores abandonaram a extração de óleo e vários produtores de perfume pararam de usar o óleo de pau-rosa em suas formulações (FIORAVANTI, 2012a). 
Em ciência e tecnologia, mesmo coisas simples podem ser difíceis, já que dependem de muitas pessoas com diferentes interesses. Esta conclusão pode parecer óbvia, mas normalmente o otimismo é que reina. Nós jornalistas e cientistas deveríamos ser mais prudentes sobre o avanço de descobertas científicas e tecnológicas. Deveríamos considerar os obstáculos e variáveis (previstas ou não) e evitar uma visão simplista, tendo em mente que mesmo ideias brilhantes podem progredir lentamente. $\mathrm{O}$ sucesso de qualquer achado científico ou tecnológico depende de muitas variáveis, principalmente tempo, dinheiro, equipamentos, conhecimentos específicos, estudantes e outros pesquisadores para trabalhar nas pesquisas promissoras - e tudo tem de estar à mão ao mesmo tempo! Uma boa dose de sorte também é bem-vinda, porque os experimentos podem dar errado, novas leis podem deter o trabalho, as agências de financiamento podem demorar para liberar os pedidos de financiamento, outros grupos de pesquisa podem publicar os resultados ou os consumidores podem simplesmente se recusar a adotar um novo produto que resultou de uma descoberta considerada brilhante enquanto estava no laboratório.

Diante de tantas variáveis, nós jornalistas não deveríamos incorporar o otimismo dos cientistas. Os pesquisadores, ao apresentarem seu projeto de pesquisa para obterem financiamento, têm de prever o que pretendem fazer e esperam encontrar - e quanto custará. Eles raramente são capazes de imaginar todos os obstáculos que terão de enfrentar para confirmar suas conclusões, convencer outros grupos sobre a importância do trabalho deles e converter suas descobertas em bens de valor econômico. Às vezes os cientistas dão aos jornalistas um prazo para apresentar novos resultados de suas pesquisas, mas geralmente esses prazos não dão certo.

É arriscado levar as previsões otimistas a sério, a exemplo da possibilidade de a supercondutividade mudar os meios de transporte, como anunciado na década de 1980, ou de o genoma humano realmente melhorar o tratamento médico, apesar de o conhecimento nessas áreas ser certamente relevante. Em países onde o sistema regional ou nacional de inovação é precário - ou seja, as conexões entre centros de pesquisa, empresas e governo 
são fracas -, o ritmo do trabalho científico é lento e a falta de continuidade da pesquisa é bastante comum. Conclusões pessimistas como as que se referem aos impactos das mudanças climáticas são igualmente arriscadas e poderiam ser apresentadas como um alerta, não como destino.

Nossa tendência é ser otimista porque confiamos no valor intrínseco da ciência, ou seja, tudo deve ir bem já que a pesquisa é feita para o bem da humanidade. Como jornalistas ou cientistas, somos treinados para ser otimistas, mas deveríamos evitar apresentar um futuro tranquilo para qualquer descoberta. Por outro lado, ser pessimista e listar as barreiras para o sucesso poderia fazer a descoberta menos relevante. Mesmo o mais cético dos jornalistas dificilmente escreveria que um cientista avançaria somente se ele estivesse realmente certo em suas conclusões, tivesse talento suficiente e conseguisse convencer outros cientistas e as agências de financiamento a apoiar sua brilhante pesquisa. Deveríamos considerar a incerteza e evitar falsas esperanças, que podem nos fazer pouco realistas, pretensiosos ou ingênuos. Em 2012, um ex- pesquisador de uma empresa farmacêutica classificou os jornalistas da Índia como em geral ineptos para descrever a complexidade envolvida no processo de testes clínicos, levando os leitores a falsas expectativas sobre novos medicamentos (RAMAMURTHY, 2012).

\section{Em campo}

O Enfoque Ampliado tem me motivado a dar mais atenção a atores não-humanos - como a caldeira e o motor usados para extrair óleo de pau-rosa em Maués, que foram resgatadas de um barco naufragado há cerca de meio século e produziam sons similares aos de uma locomotiva no meio da floresta - e tem me permitido explorar áreas diferentes, como câncer, ambiente e geofísica, de modo mais abrangente. Exemplos recentes:

- Para sugerir que uma doença não é apenas um problema médico, mas uma construção histórica e social, descrevi o modo de vida e a angústia dos moradores de um povoado de Goiás com xeroderma pigmentos, uma doença genéti- 
ca hereditária agravada com a exposição à luz do sol, os laços de solidariedade entre eles e o apoio de médicos e pesquisadores que se mobilizavam para diagnosticar novos casos e melhorar o tratamento dos já diagnosticados (FIORAVANTI, 2012b).

- Para reduzir a aridez de um relato sobre estruturas e transformações de minerais em regiões profundas da Terra, apresentei a dificuldade em se estudar o interior do planeta, a evolução histórica das visões sobre o interior do planeta e a trajetória pessoal e as motivações dos pesquisadores entrevistados (FIORAVANTI, 2012).

- Durante nove dias, acompanhei um grupo de pesquisadores em um navio de pesquisa oceanográfica, em uma viagem de coleta de sedimentos (lama) do fundo do mar, e apresentei "um pouco das engrenagens da ciência e as coisas que os papers não contam: o trabalho pesado e repetitivo, a tensão causada pelos imprevistos, as hipóteses de trabalho nascendo, o lado literalmente sujo da ciência expresso nos rostos enlameados". Vi como sutilmente emergiam "as forças geralmente ocultas da ciência, que se faz não só com boas perguntas, instituições e dinheiro, mas também com amizade, respeito e companheirismo". Um geofísico alemão observou que a coleta de sedimentos mobilizava 40 pessoas, incluindo marinheiros que ajudavam os pesquisadores, os cozinheiros e os mecânicos da casa de máquinas; os artigos científicos com os resultados do trabalho, porém, trariam o nome apenas de uns poucos cientistas (FIORAVANTI, 2013a).

- Em uma reportagem sobre genética do envelhecimento, desta vez apenas em laboratório, apresentei a rotina de pesquisadores que trabalham com o verme Caenorhabditis elegans, por meio do qual avaliam formas de controle dos genes que aceleram o metabolismo celular, e criei uma metáfora, o efeito Quasímodo, para descrever o acúmulo de agregados do aminoácido glutamina, que formam pontos verdes espalhados pelo corpo do verme 
e parecem prejudicar o movimento, como a corcunda do personagem do livro do escritor francês Victor Hugo (FIORAVANTI, 2013b).

\section{Conclusões}

O Enfoque Ampliado, por valorizar a incerteza e a diversidade de atores, pode ajudar os jornalistas a pensar de modo mais independente e os leitores a conhecer melhor os mecanismos de produção de conhecimento (RENSBERGER, 2009; MURCOT, 2009). O Enfoque Ampliado não exclui o Enfoque Clássico, que ainda pode ser útil, em versões mais moderadas, quando o tempo e o espaço para apresentar uma notícia forem escassos.

Ampliando nosso olhar, a ciência poderia finalmente tornar-se o resultado do trabalho coletivo e de mudanças contínuas - as conclusões apresentadas em um artigo científico estão longe de ser a verdade definitiva sobre um assunto. Em termos práticos, aplicar todas as possibilidades de ação do Enfoque Ampliado ao mesmo tempo pode ser impossível, mas às vezes uma ou outra pode ser útil para apresentar as novidades científicas de um modo mais realista. Finalmente, como esta abordagem está em desenvolvimento, qualquer comentário, sugestão ou correção é muito bem vindo.

\section{Referências}

CALLON, Michel. Some elements of a sociology of translation: Domestication of the scallops and the fishermen of St. Brieuc Bay. In: LAW, John (org.). Power, action and belief: a new sociology of knowledge? London: Routledge, 1986, p. 196-223.

CASTRO, Moacyr. Da planta, uma arma contra o 'Trypanosoma'. Estado de S.Paulo, São Paulo, 2 jan 2005, p. A11.

FIORAVANTI, Carlos e VELHO, Lea. Let's follow the actors! Does Actor-Network Theory have anything to contribute to science journalism? Journal of Science Communication, Turim, v. 9, n. 4, p. A02, 2010 (online). Disponível em: http://jcom.sissa.it/archive/09/04/Jcom0904\%282010\%29A02/ Jcom0904\%282010\%29A02.pdf. Acesso em: 30 out 2013.

43, abr. 2013 .

. A preciosa lama do mar. Pesquisa Fapesp, São Paulo, v. 206, p.38- 


\section{UM ENFOQUE MAIS AMPLO PARA O JORNALISMO CIENTÍFICO}

. Em um verme, as travas do envelhecimento. Pesquisa Fapesp, São Paulo, v. 212, p. 50-53, out 2013 b.

2012c.

. Abrindo a Terra. Pesquisa Fapesp, São Paulo, v. 198, p. 18-24, ago

. Fungos, instituições, máquinas e pessoas em negociação: $\mathrm{O}$

percurso do fármaco P-Mapa. 2010b. 259 f. Tese (Doutorado em Política

Científica e Tecnológica) - Instituto de Geociências, Universidade Estadual de Campinas.

$2012 b$

. Luta contra o sol. Pesquisa Fapesp, São Paulo, v. 199, p. 44-49, set

. Perfume da Amazônia. Pesquisa Fapesp, São Paulo, v. 202, p. 49.

55, dez. 2012a.

. Strengthening our natural defences: a new drug candidate and a new approach to fighting infectious diseases. The Lancet Student, Londres, setembro 2010a. Disponível em: http://www.thelancetstudent.com/ legacy/2010/09/02/strengthening-our-natural-defences-a-new-drug-candidate-and-a-new-approach-to-fighting-infectious-diseases/. Acesso em 30 out. 2013.

GOLDACRE, Ben. Bad Pharma: How Drug Companies Mislead Doctors and Harm Patients. Londres: Fourth Estate, 2012. 430 p.

KOLATA, Gina. Study Says DNA's Power to Predict Illness Is Limited. The New York Times, Nova York, 2 abr. 2013. Disponível em: http://www.nytimes.com/2012/04/03/health/research/dnas-power-to-predict-is-limited-study-finds.html? r=0. Acesso em 30 out. 2013.

LATOUR, Bruno. Give me a laboratory and I will move the world. In:

KNORR, Karin; MULKAY, Michael (eds.). Science observed. London: Sage, 1983. p.141-170.

\section{Reassembling the social: An introduction to Actor-Network}

Theory. Oxford, UK: Oxford University Press, 2005. 301 p.

- Ciência em ação: como seguir cientistas e engenheiros sociedade afora. São Paulo: Editora Unesp, 2000, 219 p.

LAW, John. On the methods of long-distance control: vessels, navigators and the Portuguese route to India. In: LAW, John (ed.). Power Action and Belief: A New Sociology of Knowledge? London, UK: Routledge and Henley, 1986. p. 234-63.

MARCUS, Gary. We are not yet ready to simulate the brain. Financial Times, Londres, 31 jan. 2013. Disponível em: http://www.ft.com/intl/cms/s/0/ b70cc5d6-6b00-11e2-9670-00144feab49a.html. Acesso em: 30 out. 2013. 
MURCOT, Toby. Science journalism: Toppling the priesthood. Nature, Londres, v. 459, n. 7250, p. 1054-1055, 2009.

MURDOCH, Jonathan. Towards a geography of heterogeneous associations. Progress in Human Geography, Manchester, v. 21, n. 3, p. 321-37, 1997. OS FRUTOS da carne. Veja, São Paulo, v. 764, p. 84, 27 abr. 1983.

PAINTER, James. Poles Apart: the international reporting of climate skepticism. Reuters Institute for the Study of Jornalism, Oxford, 2011. 216 p.

RAMAMURTHY, Nv. Inept media trials of clinical trials. Perspectives in Clinical Research. v. 3, n, 2, p. 47-49, 2012.

RENSBERGER, Boyce. Science journalism: Too close for comfort. Nature, Londres, v. 459, n. 7250, p. 1055-1056, 2009.

Revista descobre "hamburguer mágico". Estado de S.Paulo, 26 jun 1983, p. 20.

RAMOS, Yulye Jessica Romo et al. SciDev. Net Global Review 2012. SciDev.Net: Londres, 2012, 116p.

SCIENTISTS make the first plant-animal hybrid. New Scientist, Londres, 31 mar 1983, p. 888.

SHENK, David. The Limits of Genetic Testing. The Atlantic, Nova York, 3 abr 2012. Disponível em: http://www.theatlantic.com/health/archive/2012/04/ the-limits-of-genetic-testing/255416/. Acesso em: 30 out 2013.

STEWART, John. Drifting Continents and Colliding Interests: a Quantitative Application of the Interests Perspective. Social Studies of Science, Londres, v. 16, n. 2, p. 261-279, 1986.

Carlos Henrique Fioravanti

Doutor pelo Departamento de Política Científica e Tecnológica do Instituto de Geociências da Universidade Estadual de Campinas (Unicamp). É jornalista científico e escreve sobre ciência, ambiente e tecnologia desde 1985 para jornais e revistas do Brasil e de outros países. Graduado em Comunicação Social/ Jornalismo pela Universidade de São Paulo (USP), em 2007 fez o Fellowship do Reuters Institute for the Study of Journalism na Universidade de Oxford, Inglaterra. 